\title{
LIVER BIOPSY: IMPORTANCE OF SPECIMEN SIZE IN THE DIAGNOSIS AND STAGING OF CHRONIC VIRAL HEPATITIS
}

\author{
Gabriela P. CORAL(1), Aline Dal Pozzo ANTUnES(1), Ana Paula Almeida SERAFINI(1) Fernanda B. ARAUJO(2) \& Angelo Alves de MATTOS(1)
}

\begin{abstract}
SUMMARY
Liver biopsy is the gold standard method for the grading and staging of chronic viral hepatitis, but optimal biopsy specimen size remains controversial. The aim of this study was to evaluate the quality of liver specimen (number of portal tracts) and to evaluate the impact of the number of portal tracts in the staging of chronic hepatitis. Material and Methods: 468 liver biopsies from consecutive patients with hepatitis C virus and hepatitis B virus infection from 2009 to 2010 were evaluated. Results: The length of fragment was less than $10 \mathrm{~mm}$ in 43 cases (9.3\%), between 10 and $14 \mathrm{~mm}$ in 114 (24.3\%), and $\geq 15 \mathrm{~mm}$ in 311 (64.4\%); of these, in 39 (8.3\%) cases were $\geq 20 \mathrm{~mm}$. The mean representation of portal tracts was $17.6 \pm 2.1(5-40)$; in specimens $\geq 15 \mathrm{~mm}$ the mean portal tract was $13.5 \pm 4.7$ and in cases $\leq 15 \mathrm{~mm}$ was $11.4 \pm 5.0(p=0.002)$. Cases with less than 11 portal tracts were associated with $\mathrm{F} 3$, and cases with 11 or more portal tracts with F2 $(p=0.001)$. Conclusion: this study demonstrated the good quality of liver biopsy and a relationship between the macroscopic size of the fragment and the number of portal tracts.
\end{abstract}

KEYWORDS: Chronic viral hepatitis; Liver biopsy.

\section{INTRODUCTION}

The emergence of hepatology as a defined clinical medical specialty is coincident with the introduction of liver biopsy and Menghini's needle in $1958^{1}$. Clinical hepatologists were trained in liver pathology and were responsible for the foundation of the main schools of hepatology in Europe and United States ${ }^{2}$. In the past, the only way to diagnose liver disease was by liver biopsy.

Grading and staging chronic hepatitis are essential for assessing prognosis and deciding which patients should be given priority for treatment ${ }^{3}$. Liver biopsy is also helpful to rule out other diagnoses and to evaluate steatosis and iron ${ }^{4}$. Although biopsy is an invasive procedure, the risk of major complications is very low $(0.22-0.75 \%)^{5,6}$. The mortality rate attributed to the procedure is estimated in one per 10 thousand biopsies and is usually secondary to bleeding; this is even lower when the biopsy is not performed for evaluation of liver tumors ${ }^{7,8}$.

Recently, noninvasive methods were developed to assess liver fibrosis ${ }^{9}$. In this setting, measure of liver stiffness by elastography is widely used for selection of patients eligible for drug therapy ${ }^{3}$. However, liver biopsy remains the gold standard and the most used method in our setting ${ }^{10}$. In a recent study that evaluated 1,202 patients with chronic hepatitis $\mathrm{C}$ virus (HCV), elastography showed false positive results in patients with high levels of aminotransferases and obesity ${ }^{11}$. Usually, a body mass index (BMI) greater than 28 results in failure of liver stiffness measurement ${ }^{12}$. Moreover, fibroscan is a diagnostic test that depends on the experience of the operator ${ }^{13}$. Recent meta-analysis demonstrated $83 \%$ of sensitivity and $89 \%$ of specificity for the diagnosis of cirrhosis by elastography. On the other hand, in patients with moderate fibrosis, (F2 of METAVIR) sensitivity was $79 \%$ and specificity $78 \%{ }^{14}$. It's noteworthy that the guidelines for hepatitis $C$ treatment of the AASLD (American Association for the Study of Liver Diseases) and the EASL (European Association for the Study of the Liver) accepted noninvasive methods for therapeutic decision ${ }^{3,15}$.

Liver biopsy is subjected to sampling error, since a standard specimen represents only about $0.0002 \%$ of the whole liver. Then, it is essential that the sample be representative for limiting the risk of inappropriate results, but optimal biopsy specimen size remains controversial $1^{9,16,17,18}$.

Therefore, the aim of this study was to evaluate the quality of liver specimen [number of portal tracts (PT)], to correlate the sample size with the number of PT and to evaluate the impact of the number of PT in the staging of chronic viral hepatitis.

\section{MATERIALS AND METHODS}

Liver biopsies from consecutive patients with HCV and HBV infection from 2009 to 2010 were included in this study conducted

(1) Post-Graduation Course: Hepatology of Universidade Federal de Ciências da Saúde de Porto Alegre (UFCSPA).Brazil

(2) Irmandade Santa Casa de Misericórdia de Porto Alegre.Brazil.

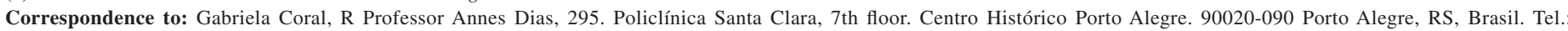
+55 (51) 32148158. E-mail: g.coral@ terra.com.br 
Coral GP, Antunes ADP, Searafin APA, Araujo FB, Mattos AA. Liver biospy: importance of specimen size in the diagnosis and staging of chronic viral hepatitis. Rev Inst Med Trop Sao Paulo. 2016;58:10.

Table 1

Portal tracts according fibrosis staging

\begin{tabular}{lcccccc}
\hline \multirow{2}{*}{ Fibrosis } & \multicolumn{5}{c}{ Number of EP } \\
\cline { 2 - 6 } & $\mathrm{N}$ & Mean & Std Deviation & Median10.50 & Minimum & Maximum \\
\hline F0 & 67 & 11.48 & 4.56 & 11.00 & 5 & 23 \\
F1 & 192 & 11.90 & 5.18 & 13.00 & 5 & 5 \\
F2 & 114 & 13.70 & 4.46 & 10.00 & 5 & 24 \\
F3 & 56 & 11.04 & 1.93 & & 5 \\
\hline
\end{tabular}

One way analysis of variance- $\left(\mathrm{F}_{\text {calc }}^{2}=5.366 ; \mathrm{p}=0.001\right)$

in a tertiary hospital in southern Brazil (Irmandade Santa Casa de Misericórdia de Porto Alegre-ISCMPA).

Patients under the age of 18 were excluded, as well as those with other causes of chronic liver disease.

All biopsies were guided by ultrasonography using an $18 \mathrm{G}$ disposable Tru-Cut needle. The specimens were fixed in $10 \%$ formalin and evaluated with respect to size $(\mathrm{mm})$. When two or more fragments were obtained, the larger was analyzed. Fragmentation of the specimen was also assessed. Samples were classified as $\geq 15 \mathrm{~mm}$ and $<15 \mathrm{~mm}$ for statistical analysis.

Liver biopsies were routinely stained with Hematoxylineosin, Perls and Masson's trichrome, and evaluated by the same hepatopathologist who was blinded to the size of specimen and clinical data. The number of PT was evaluated in all cases, excepted in those with cirrhosis, because of changes in liver architecture, annulling the individualization of $\mathrm{PT}^{19}$. Specimens with less than five PT were considered inadequate for analysis ${ }^{20}$. Biopsies were classified according to METAVIR score ${ }^{21}$.

This study was approved by the Institutional Review Board of ISCMPA

Statistical analysis was performed using SPSS software (Statistical Package for Social Sciences) version 17.0. Quantitative variables were described using mean and standard deviation (symmetrical distribution) or median (asymmetric distribution). Categorical variables were described by absolute and relative frequencies. The Chi-square and Pearson, Fisher's exact test and One Way analysis of variance test were used for statistical analysis. A $p$ value $\leq 0.05$ was considered statistically significant.

\section{RESULTS}

Four hundred and sixty-eight liver biopsies were evaluated. The mean age of patients was 57.7 years (18-78). Two hundred and thirty-eight patients were female $(50.8 \%)$.

Fragment size was less than $10 \mathrm{~mm}$ in 43 cases (9.3\%), range between 10 and $14 \mathrm{~mm}$ in $114(24.3 \%)$, and was $\geq 15 \mathrm{~mm}$ in $311(64.4 \%)$; of these, in $39(8.3 \%)$ cases were $\geq 20 \mathrm{~mm}$. The mean length of fragments was $13.3 \pm 4.2 \mathrm{~mm}$. The fragmented specimens were $21 / 468(4.5 \%)$, and in these cases the report pointed out the possible limitation of the staging performed.

Of the 468 cases, 39 (8.3\%) had a diagnosis of liver cirrhosis; therefore, the specimens considered for assessment of number of PT was 429. The mean representation of PT per biopsy was $17.6 \pm 2.1$ (540 ) and the median was 15 . Moreover, in specimens $\geq 15 \mathrm{~mm}$ the mean PT was $13.5 \pm 4.7$, and in cases $<15 \mathrm{~mm}$ it was $11.4 \pm 5.0(p=0.002)$. The number of PT per sample was as follows: 5 PT in 20 cases $(4.7 \%)$, 6 to 8 in 88 cases $(20.6 \%), 9$ to 10 in 67 cases $(15.5 \%)$, and $\geq 11$ PT in $254(59.3 \%)$.

Fibrosis stage was scored as follows: F0 in 67 patients (14.3\%), $\mathrm{F} 1$ in $192(41.0 \%), \mathrm{F} 2$ in $114(24.4 \%), \mathrm{F} 3$ in $56(12.0 \%)$, and $\mathrm{F} 4$ in 39 $(8.3 \%)$. The necroinflammatory activity was classified as absent (A0) in 32 cases $(6.8 \%)$, mild (A1) in 215 cases $(45.5 \%)$, moderate (A2) in 185 (39.1\%), and severe (A3) in $36(7.6 \%)$. Steatosis was present in $41.6 \%$ and iron in $20.5 \%$.

The association between fibrosis staging and the number of PT is shown in Table 1 . There was a statistically significant difference indicating that the mean of PT in samples with F2 $(13.7 \pm 4.4)$ was significantly higher when compared to other stages (F0: $11.5 \pm 4.6-p$ $<0.01 ; \mathrm{F} 1: 11.9 \pm 5.2-p<0.05 ; \mathrm{F} 3: 11.0 \pm 4.9-p<0.001)$.

There was a significant association between fibrosis stage F3 and representation of less than $11 \mathrm{PT}$, and an association between F2 and 11 or more PT $(p=0.001)$ (Table 2$)$.

Table 2

Fibrosis staging according portal tracts: stratified sample

\begin{tabular}{lccc}
\hline Fibrosis & \multicolumn{2}{c}{ Portal Tracts } & Total \\
\cline { 2 - 3 } & $<11$ & $\geq 11$ & \\
\hline F0 & $32(18.5 \%)$ & $32(12.6 \%)$ & $64(15 \%)$ \\
F1 & $81(46.8 \%)$ & $111(43.9 \%)$ & $192(45.1 \%)$ \\
F2 & $30(17.3 \%)$ & $84(33.2 \%)$ & $114(26.8 \%)$ \\
F3 & $30(17.3 \%)$ & $26(10.3 \%)$ & $56(13.1 \%)$ \\
\hline Total & $173(100 \%)$ & $253(100 \%)$ & $426(100 \%)$ \\
\hline
\end{tabular}

Chi-square and Pearson $(p=0.001)$ 


\section{DISCUSSION}

Liver biopsy is a diagnostic method widely used for staging of chronic hepatitis, despite the rising of noninvasive methods. However, one of its limitations is sampling variability. In order to minimize sampling error, biopsy needs to be representative of the whole liver ${ }^{7}$.

The size considered ideal for histological analysis is under debate in the literature ${ }^{22}$. Some studies suggest that a biopsy of $10-15 \mathrm{~mm}$ in length, with 4-6 PT is sufficient for staging of chronic hepatitis ${ }^{17,18,23}$ whereas, other authors suggest a minimum size of 20 to $25 \mathrm{~mm}$ and at least $11 \mathrm{PT}^{9,16}$

SCHIANO et al $^{18}$ analyzed 100 biopsies and didn't find a significant difference in fibrosis stage when evaluating different sizes of the same liver specimen. Ninety-four per cent of the specimens of $10 \mathrm{~mm}$ received the same staging or just one degree of difference when compared with the $20 \mathrm{~mm}$. On the other hand, COLLOREDO et al..$^{9}$ studied 161 biopsies from patients with chronic hepatitis considering only specimens of 30 $\mathrm{mm}$ or more. These fragments were first examined in their original size and then reduced in size to be reanalyzed $(20 \mathrm{~mm}, 15 \mathrm{~mm}$ and $10 \mathrm{~mm}$ ). The necroinflammatory activity and fibrosis were more often considered as discrete when smaller size was analyzed. A sample larger than or equal to $20 \mathrm{~mm}$ and representation of at least 11 full PT was considered necessary for accurate evaluation.

BEDOSSA et al. ${ }^{16}$ also compared the results of staging the same biopsy in two different sizes: $25 \mathrm{~mm}$ and $15 \mathrm{~mm}$. In agreement with the previous study, they demonstrated that larger fragments allowed to assess staging more accurately.

In the present study, in $90.7 \%$ cases the fragment had more than 10 $\mathrm{mm}$, the minimum size recommended by BEDOSSA et al., in the study that validated the METAVIR classification ${ }^{21}$. Similarly, in this study, the average number of PT was 17.6 and the median was 15, demonstrating a good quality of liver biopsy.

Importantly, a systematic review evaluating the quality of liver biopsies demonstrated that the mean PT represented was $7.5 \pm 3.4$ in 10,027 biopsies. In this systematic review, the correlation between fragment size and number of PT was low (Spearman $r=0: 45)^{22}$. In this study, we found a correlation between PT and size of fragment.

In the present study, $40.7 \%$ of the sample had less than $11 \mathrm{PT}$. However, it was shown that advanced fibrosis (F3) was even linked to the representation of less than 11 PT. Thus, although it has been shown that 11 PT would be ideal minimum number for staging ${ }^{9,16}$, this study is consistent with other studies that suggest that less than 11 PT may be suitable ${ }^{17,18,23}$.

Regarding the liver biopsy sample size , attention should be drawn to the fact that the vast majority of clinical trials in chronic hepatitis did not mention the number of PT represented ${ }^{22,24}$.

We conclude that liver biopsy in real life, in a general hospital, has good quality, showing in almost all cases, the minimum size suggested for the diagnosis and staging. A relationship between the macroscopic size of the fragment and the number of PT represented has also been demonstrated. Furthermore, in this study, representation of less than 11 and more than 5 PT probably did not adversely influence the staging.
Abbreviations:
PT- Portal tracts
$\mathrm{HCV}$ - Hepatitis C virus
BMI- Body Mass Index

AASLD- American Association for the Study of Liver Diseases

EASL- European Association for the Study of the Liver

ISCMPA- Irmandade Santa Casa de Misericórdia de Porto Alegre

\section{REFERENCES}

1. Menghini G. One-second needle biopsy of the liver. Gastroenterology. 1958;35:190-9.

2. Castera L, Pinzani M. Biopsy and non-invasive methods for the diagnosis of liver fibrosis: does it take two to tango? Gut. 2010;59:861-6.

3. Ghany MG, Strader DB, Thomas DL, Seeff LB, American Association for the Study of Liver Diseases. Diagnosis, management, and treatment of hepatitis C: an update. Hepatology. 2009;49:1335-74.

4. Kleiner DE. The liver biopsy in chronic hepatitis C: a view from the other side of microscope. Seminar Liver Dis. 2005;25:52-64.

5. Huang JF, Hsieh MY, Dai CY, Hou NJ, Lee LP, Lin ZY, et al. The incidence and risks of liver biopsy in non-cirrhotic patients: an evaluation of 3806 biopsies. Gut. 2007;56:736-7.

6. Szymczak A, Simon K, Inglot M, Gladysz A. Safety and effectiveness of blind percutaneous liver biopsy: analysis of 1412 procedures. Hepat Mon. 2012;12:32-7.

7. Rockey DC, Caldwell SH, Goodman ZD, Nelson RC, Smith AD. AASLD position paper. Liver biopsy. Hepatology. 2009;49:1017-44.

8. West J, Card TR. Reduced mortality rates following elective percutaneous liver biopsies. Gastroenterology. 2010;139:1230-7.

9. Colloredo G, Guido M, Sonzogni A, Leandro G. Impact of liver biopsy size on histological evaluation of chronic viral hepatites: the smaller the sample, the milder the disease. J Hepatol. 2003;39:239-44.

10. Castera L, Bedossa P. How to assess liver fibrosis in chronic hepatitis C: serum markers or transient elastography vs. liver biopsy? Liver Int. 2011;31 Suppl 1:13-7

11. Platon ML, Stefanescu H, Feier D, Maniu A, Badea R. Performance of unidimensional transient elastography in staging chronic hepatits C. Results from a cohort of 1,202 biopsied patients from one single center. J Gastrointestin Liver Dis. 2013;22:157-66.

12. Myers RP, Pomier-Layrargues G, Kirsch R, Pollett A, Duarte-Rojo A, Wong D, et al. Feasibility and diagnostic performance of the FibroScan XL probe for liver stiffness measurement in overweight and obese patients. Hepatology. 2012;54;199-208.

13. Armstrong MJ, Corbett C, Hodson J, Marwah N, Parker R, Houlihan DD, et al. Operator training requirements and diagnostic accuracy of Fibroscan in routine clinical practice. Postrag Med J. 2013;89:685-92.

14. Tsochatzis EA, Gurusamy KS, Ntaoulas S, Cholongitas E, Davidson BR, Burroughs AK. Elastography for the diagnosis of severity fibrosis in chronic liver disease: a meta-analysis of diagnostic accuracy. J Hepatol. 2011;54:650-9.

15. Pawlotsky JM. New hepatitis $\mathrm{C}$ therapies: the toolbox, strategies, and challenges. Gastroenterology. 2014;146:1176-92.

16. Bedossa $P$, Dargerè $D$, Paradis V. Sampling variability of liver fibrosis in chronic hepatitis C. Hepatology. 2003;38:1449-57. 


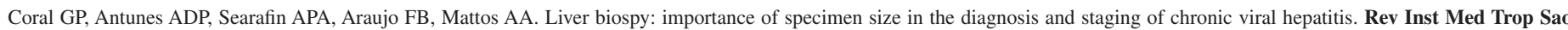
Paulo. 2016;58:10.

17. Ryder SD, Irving WL, Jones DA, Neal KR, Underwood JC, Trent Hepatitis C Study Group. Progression of hepatic fibrosis in patients with hepatitis C: a prospective repeat liver biopsy study, Gut. 2004,53:451-5.

18. Schiano TD, Azeem S, Bodiam CA, Bodenheimer HC Jr, Merati S, Thung SN, et al. Importance of specimen size in accurate needle liver biopsy evaluation of patients with chronic hepatitis C. Clin Gastroenterol Hepatol. 2005;3:930-5.

19. Sciot R, Staessen D, Van Damme B, Van Steenbergen W, Fevery J, De Groote J, et al. Incomplete septal cirrhosis hitopathological aspects. Histopathology. 1988;13:593603.

20. Sporea I, Sirli R, Popescu A, Cornianu M, Manciu C, Focsa M. The quality of the fragment obtained by liver biopsy for staging chronic hepatites. J Gastrointestin Liver Dis. 2007;16:263-6
21. Bedossa P, Poynard T. An algorithm for the grading of activity in chronic hepatits C. The METAVIR Cooperative Study Group. Hepatology. 1996;24:289-9.

22. Cholangitas E, Senzolo M, Standish R, Marelli L, Quaglia A, Patch D, et al. A systematic review of the quality of liver biopsy specimens. Am J Clin Pathol. 2006;125:710-21.

23. Bravo AA, Sheth SG, Chopra S. Liver biopsy. N Engl J Med. 2001;344:495-500.

24. Castera L. Noninvasive methods to assess liver disease in patients with hepatitis B or C. Gastroenterology. 2012;142:1293-302.

Received: 03 March 2015

Accepted: 19 May 2015 